of false joint, but for diaphysitic fractures he under. stands the utility of massage less, as in such cases one should always fear the formation of false joints. Dr. Marc Sée stated that he obtained the same results as Dr. Lucas Championnière by means of the elastic band. He considers this as being a great deal more simple, and, in any case, it never requires the sittings of massage of one hour and a half, which would constitute a serious obstacle to the introduction of this method in practice.

Dr. Féréol lately read a paper at the Société Médicale des Hôpitaux, in which the author, Dr. Devalz, of Eaux-Bonnes, intended to show that typhoid fever may be propagated through the air as well as by the fluid or solid substances introduced into the stomach. The following illustrative case is given by the author: A lady arrived at Eaux-Bonnes from Paris with the primary symptoms of typhoid fever, of which she was cured at the end of four weeks. Three daughters of the proprietor of the hotel in which the lady was staying, who occupied a room adjoining the privy in which the dejections of the patient were thrown, successively fell ill with the malady. The author thinks that he has a right to conclude from this circumstance that in this case, at least, the disease was communicated through the air which circulated freely between the privy and the room occupied by the patients, every precaution having been taken to prevent contamination of the food or drinkingwater.

At the same meeting Professor Hayem read a very interesting article giving the results of his researches on urobilinuria. The author demonstrated how, by the aid of the spectroscope, urobiline may be recognized in the serum of the blood and in the urine. In the second part of his work, Professor Hayem devotes some considerations to clinical results. According to him, the excretion of an abnormal quantity of urobiline constitutes urobilinuria. This phenomenon may be transitory, or it may be intermittent, or it may present itself in a permanent manner. When the affection is slight, the color of the urine is scarcely altered, but when well marked, we have the hemapheic urine of Gubler. Urobiline is found in the urine, either alone, or associated with a more or less considerable quantity of biliary pigments. It is found constantly during the periods of asystolic cardiac affections. It is frequently met with in intoxications, diseases of the liver, cerebral affections, and in certain chronic maladies. It is also frequently met with in the greater part of acute affections. Dr. Hayem does not believe that urobiline alone can produce jaundice. Finally he had been able to establish, in all the cases in which he observed urobilinuria, a venous stasis of the liver with slight catarrh of the biliary ducts, and with infiltration or fatty degeneration of the hepatic cells. In the third part of his paper, Dr. Hayem studied the origin of urobiline. For the learned Professor, the diseased liver, instead of secreting normal pigments, secretes urobiline, which, according to certain clinical facts, would pass directly from the biliary canalicules into the blood. In conclusion, Dr. Hayem establishes the prognostic value of the symptom of urobilinuria as follows: When temporary it indicates temporary modifications of the hepatic circulation. When permanent, it indicates infiltration or the fatty degeneration of the hepatic cells.

The powerfully modifying action of caustics has always been considered a precious resource in surgical practice. According to the Courrier Médical Dr. Jules Felix, of Brussels, finding a great number of inconveniences attending the ordinary caustics in use, proposes a paste as a substitute for them. The following is the formula of the paste: Powdered starch 37 grams, wheat flour I I 2 grams, bichloride of mercury I gram, dried chloride of zinc I Io grams, pure iodol to grams, croton chloral to grams, bromide of camphor ro grams, crystallized carbolic acid ro grams; all to be mixed up in a glass mortar, the ingredients being well pulverized separately, and gradually add to the whole the quantity of distilled water necessary to obtain a homogeneous paste, which keeps in a perfect state of preservation for an indefinite time. When required to be used the quantity necessary should be pressed in the hand previously moistened, and the paste could then be pressed into any shape or form. The author claims the following advantages for this preparation: I. Pain very supportable and slightly intense, without any general reaction. 2. Production of an eschar which is hard and well limited, detaching itself quickly or allowing itself to be easily removed with a sharp instrument or by scraping. 3. Marked modifying and antiseptic action. 4. Powerful hæmostatic. 5. Easy to be manipulated and put into any form according to circumstances. 6. This caustic not being fusible, nor deliquescent, may be easily applied to any part, where it may remain more or less long time (from 6 to 24 hours), according to the intensity of action the surgeon may wish to obtain. 7. The eschars fall off in a few days, by the application of glycerine with or without carbolic acid.

A. B.

\section{DOMESTIC CORRESPONDENCE}

\section{SALIVARY FISTULA.}

In June, I 885, I excised a sebaceous tumor which had been located mostly in the space bounded by the angle of the jaw in front, and the lobe of the ear above. The tumor had lain partly over the parotid gland in front of the lobe of the ear. I had expected to be able easily to lift the tumor out of its bed after making a free incision; but I found it very tightly bound down and intimately connected by areolar tissue-with the surrounding tissues-making a careful dissection necessary to dislodge it. The operation was very bloody and my assistance was indifferent, but the tumor was ultimately dislodged. The wound seemed to be healing kindly until one day my patient informed me that at times a gush of fluid flowed from what was a small remnant of the wound. I became aware that I had a salivary fistula to contend with. I must have wounded the parotid gland with the scalpel in dissecting out the tumor and in removing what was simply a deformity, I had substituted an affliction which 
was an active nuisance far more troublesome than the original deformity.

Examination showed the existence of a fistulous channel with a diameter of about three-sixteenths of an inch, and from this channel the saliva flowed freely whenever food or any sapid substance was taken into the mouth. My patient's complaint was temperate though mildly reproachful, and he was solicitous for relief from this new affliction.

I kept my patient's mind occupied for a time, in what I knew to be useless efforts to heal the sinus unti! I might think out an efficient scheme. After carefully looking over the methods of Ericson and Bryant I concluded that the use of the cautery in their cases was irrational-and also that the nature of the salivary sinus such as my case afforded data to-which might be fitted a rational method of cure.

The healing of a salivary fistula is prevented by the intermittent flow of saliva-which bathes the walls of the sinus, and prevents union. When an acute inflammation occurs, in the parenchyma of a gland, the cells affected by this inflammation cease to form their particular secretion until the inflammation becomes resolved. Therefore to heal a salivary fistula, it is necessary to induce an acute inflammation in the secreting cells of the gland, and at the same time an adhesive inflammation of the walls of the sinus, that obliteration of the sinus by adhesion may be effected before the cells of the gland resume their proper function-by the abatement of the inflammation affecting them. The actual cautery induces such an inflammation as is needed, both in the cells of the gland and in the walls of the sinus; but it does more, it kills what tissue it touches and before union can occur the sloughs must come away; and by this time, the function of the secreting cells is reestablished and the same state of affairs exists as before the use of the cautery.

In my case, I filled the sinus completely with flyblister, and let it remain several hours. After removing the fly-blister, the sinus was pulled together with adhesive straps. This resulted in a partial union of the sinus. I next painted the sinus to its bottom with cantharidal collodion and again pulled it together with adhesive straps, and the result was a complete union of the walls of the sinus, and permanent cure of the difficulty, as two years have now elapsed and the channel has not re-opened.

These remarks apply of course only to such cases as are not complicated with obstructions in the duct proper of the gland and to cases only of traumatism directly to the gland itself.

Silverton, Colo., July 16,1887 .

$$
\text { J. W. Brown, M.D. }
$$

\section{INTUBATION.}

Dear Sir:-I have devised the following improvement on the O'Dwyer intubation set, which entirely obviates the difficulty of properly adjusting the extractor:

An eye should be drilled in the anterior or stationary jaw of extractor, about its centre, and from the inner opening a groove cut to the tip of jaw suffi- cient to accommodate the double thread coming from the tube. The thread hole in tube should be drilled about $I$ inch from neck of tube, having its external opening countersunk to receive knot on thread. Both ends of thread should emerge from upper opening of tube, the obturator being grooved for their reception. Now by introducing the free ends of thread into the eye of extractor, the extractor is threaded into the tube with facility and precision.

For the application of nitrate silver solutions I suggest the following: To one end of a small glass tube attach the bulb of a medicine dropper, to the other a camel's-hair pencil, the quill of which is made pervious; or a piece of sponge or cotton may be made to answer for the brush end. A U.shaped bend should be made near the bulb. With this the solution may be applied in any quantity without danger of the disagreeable dripping so common with an ordinary brush. Respectfully,

Indianapolis, May 12, 1887 .

W. V. Morgan, M.D.

\section{NEW INSTRUMENTS.}

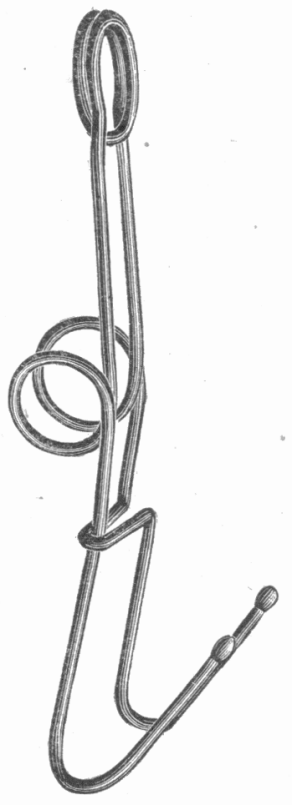

IMPROVED NASAL SPECU-
LUM.

BY I. W. FINK, M.D. HILLSBORO, ILL.

Necessity is said to be the mother of invention, therefore appears the accompanying cut, representing an instrument brought into existence by me for the examination of the nasal passage--a Nasal Speculum. Like many other instruments intended for the same purpose, it has its good qualities as well as its faults.

If it is worthy of merit, it is worthy of publication, and the medical profession is entitled to its use.

\section{NECROLOGY.}

\section{J. W. D. OSGOOD, M.D.}

Jonathan Walter Dandola Osgood, M.D., of Greenfield, Mass., was born in Gardner July 29, 1802 . He was the son of Rev. Jonathan Osgood, M.D.-a graduate of Yale, and for many years the only minister and physician of his town-and Orange Wadsworth, of Farmington, Conn. The subject of this notice was graduated at Dartmouth College in 1823 . 